\title{
MICROTERRITORIALIDADE E CONTROLE SOCIETAL
}

JÚLIA MORETTO AMÂNCIO

LIZANDRA SERAFIM

MONIKA DOWBOR

$\mathrm{O}$ artigo apresenta resultados de uma pesquisa empírica que revelou uma intensa atuação de controle societal relacionada com a provisão de serviços públicos de saúde e assistência realizada em regiões de baixa renda em São Paulo. O foco microterritorial adotado permitiu tornar visíveis os atores coletivos que, contrariando as proposições da literatura, não constituem protagonistas dos seus respectivos setores e não restringem ações de controle societal aos espaços de participação institucionalizada.

362 ção; saúde e assistência social.

Recebido: 28/02/2011 Aprovado: 05/09/2011

\section{MICRO-TERRITORIALITY AND SOCIETAL CONTROL}

The paper presents results of an empirical research that revealed the existence of intense societal accountability actions related to service delivery in health and social assistance performed in low income regions in the city of Sao Paulo. The micro-territorial approach adopted by the research gave visibility to collective actors that, contrary to what might be expected based on the literature, are not the protagonists of their respective sectors and do not restrict their societal accountability actions to institutionalized participatory spaces.

Keywords: societal accountability; service delivery; participation; health and social assistance. 


\title{
MICROTERRITORIALIDADE E CONTROLE SOCIETAL*
}

\author{
Júlia Moretto Amâncio \\ Lizandra Serafim \\ Monika Dowbor
}

A provisão de serviços públicos de saúde e assistência social é objeto de frequentes ações de controle societal realizadas por atores inesperados pela literatura, as associações de bairro $^{1}$. Os resultados desta pesquisa, conduzida em torno das Unidades Básicas de Saúde (UBSs) de São Paulo, desvela três aspectos importantes: recoloca o debate sobre ação coletiva no microterritório, nível pouco tratado pela literatura sobre a participação; amplia a análise para fora

\footnotetext{
* Este artigo é resultado de pesquisa "Reforma de serviços públicos - O papel da ação coletiva e da accountability social (Delhi e São Paulo)" produzida pela equipe de pesquisadoras do Centro Brasileiro de Análise e Planejamento (Cebrap) e do Institute of Development Studies (IDS), sob a coordenação de Peter Houtzager. A realização da pesquisa foi possível em função do apoio do Development Research Centre for the Future State do IDS e foi financiada pelo Department for International Development (Reino Unido). Durante o processo da elaboração do artigo, recebemos valiosas contribuições de Adrian Gurza Lavalle, Eduardo Marques, Peter Houtzager, Ernesto Isunza Vera, Renata Bichir e pesquisadores do Núcleo de Jovens Pesquisadores do Cebrap, aos quais estamos muito gratas, assumindo todos os possíveis erros como tão-somente de nossa responsabilidade.

${ }^{1}$ Conforme será desenvolvido posteriormente, entendemos por controle societal "a incidência de cidadãos sobre os processos decisórios seja mediante o fornecimento de informação, a determinação de prioridades, a implementação ou como formas de avaliação e supervisão" (Gurza Lavalle e Isunza Vera, 2010, p.31).
} 
dos espaços institucionalizados de participação e apresenta um ator não previsto pela literatura setorializada de políticas públicas: o generalista.

A pesquisa foi realizada entre 2007 e 2008 em 45 regiões de baixa renda de São Paulo, e buscou identificar ações coletivas que visavam à melhoria da qualidade dos serviços nas áreas de saúde e assistência social, por meio dos programas Saúde da Família (PSF) e Renda Mínima (RM). Ela evidenciou que nesses microterritórios, onde ocorre a provisão dos serviços públicos básicos, há associações locais que realizam uma ampla variedade de ações de controle societal, que vai dos protestos ao encaminhamento administrativo de suas demandas para exigir melhorias nos serviços distribuídos em suas comunidades. Sua existência e perfil não podem ser depreendidos, no entanto, das trajetórias dos setores pesquisados. Diferentemente do que alegam as literaturas sobre participação cidadã e setorial, a pesquisa 288 aponta que não é o tradicional movimento popular de saúde que faz o controle societal do PSF no microterritório - apenas $11 \%$ dos atores possuem uma ligação com aquele movimento - e que, apesar da falta de registro sobre usuários organizados na assistência social, sobre o RM também incidem as ações de controle dos atores locais. Em outras palavras, os atores detectados pela pesquisa não constituem os protagonistas do setor de saúde nem são vinculados a qualquer trajetória setorial específica: trata-se das associações de bairro, eclipsadas pela literatura, de perfil generalista por exercerem controle societal sobre os diversos serviços públicos.

Na pesquisa, foram registradas também diferenças setoriais em termos de tipos de ações desenvolvidas sobre cada programa. Enquanto que, no caso do PSF, os atores utilizam mais frequentemente repertórios contenciosos, como a realização de manifestações públicas, protestos, abaixo-assinados e assembleias na comunidade; no caso do RM, observa- 
mos que os atores buscaram mais informação e acionaram em maior medida o judiciário.

As proposições das literaturas que tangenciam as interações entre os atores da sociedade civil e aqueles do Estado em processos da implementação de políticas públicas e provisão de serviços, invisibilizam a política no microterritório, tratando apenas dos níveis centralizados do processo decisório das políticas. Assim, a literatura sobre a participação se concentra primordialmente nos espaços participativos (conselhos setoriais, conferências, Orçamento Participativo etc.) em detrimento de outras formas de interação dos atores coletivos com o Estado, voltando-se para os níveis macroterritoriais de análise (municipal, estadual ou nacional), onde esses espaços existem e/ou são previstos por lei e onde operam os atores coordenados e centralizados. Essa literatura tende também a trabalhar setorialmente, foco que compartilha com o das políticas públicas, e, em função disso, credita às trajetórias setoriais a capacidade explicativa. Por fim, a literatura sobre accountability social, como forma das organizações da sociedade civil exercerem o controle sobre o Estado, privilegiou a análise da atuação nos níveis macro, em que os custos reputacionais entre as organizações da sociedade civil e o Estado explicavam a maior parte dos episódios.

As literaturas aqui referidas poderiam, no limite, pelo seu foco setorial, prever a presença dos atores coletivos ligados ao setor de saúde exercendo pressão sobre o Estado no microterritório, onde atua o tradicional movimento popular de saúde, mas não oferecem instrumental analítico para lidar com a fase da implementação da política pública fora dos espaços institucionalizados de participação. Partindo do desafio de entender as dinâmicas entre os atores coletivos e a provisão local de serviços públicos e suas melhorias, e levando em consideração que não existe evidência empírica de que formas menos rigorosas de controle societal não con- 
tribuam para a melhoria da provisão de serviços públicos e das políticas públicas em geral, foi estabelecida a seguinte hipótese, deduzida das análises setoriais: a implementação do PSF no setor de saúde seria objeto de intenso controle societal nas regiões com presença marcante do movimento popular de saúde, enquanto o programa de assistência social, por falta de atores coletivos representando os usuários, seria desprovido de tais ações de controle.

A incidência da ação dos atores coletivos sobre a provisão de serviços públicos encontrou sua expressão analítica no conceito de controle societal (Gurza Lavalle e Isunza Vera, 2010), que permite incluir diversos tipos de ação dos atores coletivos. O conceito aponta também para o limite da discussão aqui desenvolvida: considerando a ideia de que o controle social é de fato um sistema (Isunza Vera, 2010), e que, portanto, vai muito além do nível local da provisão de serviços, estamos iluminando uma parte do controle societal que acreditamos ser

290 fundamental para o debate acerca das possibilidades e limites da participação e da qualidade de serviços públicos.

O texto se inicia com o debate da literatura para, na segunda seção, apresentar, em linhas gerais, as trajetórias de saúde e assistência social baseadas nas análises setoriais para apontar as hipóteses construídas sobre o controle societal de atores coletivos no nível microterritorial. A terceira parte do texto explicita o desenho da pesquisa empírica e as escolhas metodológicas. Na quarta seção, encontra-se a discussão dos dados, e na conclusão indicam-se os desafios para novas pesquisas sobre microterritorialidade e controle societal.

\section{A política microterritorial: breve discussão com a literatura}

Iniciaremos a discussão proposta percorrendo a literatura fundamental sobre participação social, buscando ali identificar a presença de atores coletivos organizados no nível microterritorial e de ações empreendidas por tais atores 
pela melhoria da provisão de serviços públicos, compreendendo a fase de implementação da política pública.

As literaturas sobre movimentos sociais e participação cidadã têm uma origem comum nas organizações de base, com especial atenção àquelas que se constituíram nos anos 1970 nas periferias das grandes cidades, tais como os conselhos populares de saúde, as Comunidades Eclesiais de Base (CEBs), os sindicatos, os clubes de mães, as Sociedades Amigos de Bairro (SABs), as pastorais organizadas pela igreja católica etc. Na maior parte das vezes, elas foram tratadas na chave da autonomia e da cultura política, e só marginalmente em sua relação com o Estado e atores políticos como partidos ou sindicatos, como em Boschi (1987), Sader (1988) e Doimo (1995).

Nos termos de Gurza Lavalle e Bueno, se nos anos 1970 e 1980 tais atores coletivos "foram observados com altas expectativas no debate acadêmico como novos atores da transformação social" tendo sido pensados, sobretudo nos anos 1980, "no registro dos movimentos sociais, especificamente como movimentos de bairro alinhados dentro do campo dos movimentos populares" ([no prelo], p. 5); já nos anos 1990:

as associações de moradores perdem a centralidade no debate acadêmico, pois suas reivindicações eminentemente distributivas, sua baixa visibilidade e suas capacidades mínimas para disputar a agenda pública tornaram-nas pouco palatáveis às exigências normativas que definem o teor do debate no Brasil sobre a sociedade civil nesses anos (Gurza Lavalle e Bueno, [no prelo], p. 6).

Com a emergência de novas formas de interação entre Estado e atores coletivos, o debate sobre movimentos sociais na chave da autonomia-cooptação sofre um esvaziamento nos anos 1990 (Tatagiba, 2007), dando lugar à categoria de sociedade civil enquanto lugar ocupado por atores múltiplos 
(Gurza Lavalle, 2003; Abers e Von Bülow, 2011). O foco dos estudos empíricos passa a ser a relação com o Estado por meio dos espaços participativos em criação e expansão no período, dos processos de construção institucional dos espaços, de seu impacto na cultura política e na democratização da gestão local, de sua capacidade distributiva e eficiência deliberativa e das dinâmicas de interação entre os atores no interior dos espaços (Baierle, 2000; Cortês, 1998; Lüchmann, 2002; Tatagiba, 2007; Silva, 2003; Avritzer, 2003; Marquetti, 2003; Navarro, 2003; Fuks, 2007).

A disposição normativa dessa literatura em observar o potencial transformador de tais espaços, em sua capacidade de democratizar as políticas públicas produzidas, reforçou a formulação destas como etapa privilegiada (Tatagiba, 2007), ocorrendo em espaços centralizados no nível municipal. Como consequência, não avançou em estabelecer distinções analíticas sobre a incidência da participação em outras fases 292 da política pública, além de prestar pouca atenção em interações importantes, como a participação no nível submunicipal e em espaços de fiscalização e monitoramento da execução das políticas e programas como conselhos gestores de UBSs ou caravanas de fiscalização de obras do Orçamento Participativo. Com isso, as organizações fundadas em microterritórios e sua ação política local se tornam invisíveis, e as organizações mais estruturadas e articuladas em nível municipal em suas relações com o governo na construção das políticas públicas, ocupam lugar central das análises.

Considerando a organização dos conselhos de políticas públicas específicas, como no Sistema Único de Saúde e no Sistema Único de Assistência Social, as análises sobre o tema se organizam também de maneira setorial, focando em atores organizados especificamente por áreas de políticas, tais como movimento de saúde, de moradia etc. (Raichelis, 2000; Mestriner, 2005; Teixeira, Kayano e Tatagiba, 2007; Teixeira et al., 2007) A mesma tendência observa-se na lite- 
ratura sobre políticas públicas (Cohn e Elias, 2005; Yazbek, 2004b; Sposati, 2007), que tende a ser especializada setorialmente $^{2}$, conforme indicam Souza (2003) e Marques (2005).

A partir de 2003, com a criação de novos conselhos e conferências pelo governo Lula, tornou-se maior a preocupação da literatura em compreender as experiências de nível nacional (Pogrebinschi, 2010; Silva, 2009; Cortês et al., 2009). Aqui a atenção se volta a atores cada vez mais organizados nacionalmente, seja na relação com o Executivo federal, seja na definição de diretrizes das políticas públicas, ou na relação com suas bases ${ }^{3}$. As dinâmicas microterritoriais são invisibilizadas ainda mais por esta literatura, focada no âmbito federal e nas dinâmicas circunscritas aos espaços constituídos neste nível.

Além de conselhos de políticas públicas, o Orçamento Participativo (OP) também constituiu um espaço estudado por essa literatura desde os anos 1990, como uma das grandes inovações na gestão democrática local. Por ser um dispositivo de participação baseado no território e organizado a partir dos bairros, envolvendo diretamente organizações locais em plenárias regionais, ele foi retratado pela literatura a partir de questões referentes às dinâmicas políticas locais, que influenciam as disputas e o exercício da representação naquele espaço (Abers, 2000; Baierle, 2000; Baiocchi, 2001). No entanto, o enfoque está no impacto exercido por tais dinâmicas sobre o funcionamento do espaço em si e suas

\footnotetext{
${ }^{2}$ Entre as exceções, vale notar os trabalhos sobre institucionalismo com foco no federalismo de Arretche, (2002) e Melo (2005) ou ainda o trabalho pioneiro de Marques (2005) que propõe o modo de análise de políticas públicas pautado nas redes, atores e instituições.

${ }^{3}$ Vale registrar outro processo em curso na literatura brasileira: a "volta" aos movimentos sociais (Tatagiba e Teixeira, 2005; Silva, 2010) que busca compreender a combinação de estratégias adotadas pelos mesmos para incidir nas políticas públicas; os conflitos e impactos trazidos pela experiência de participação institucional sobre suas formas de organização e sobre sua capacidade de mobilização e representação desde as bases. Esse processo, ainda incipiente, não envolve a volta ao microterritório.
} 
consequências para a definição do investimento público municipal. A análise continua centrada na estrutura institucional do OP, criada pelo Estado para promover a participação, envolvendo o microterritório em seu arcabouço institucional próprio. O objetivo da relação estabelecida também é claro: incidir em um aspecto da política pública (investimento público), e não a melhoria da qualidade dos serviços ou políticas públicas implementadas em nível microterritorial. A relação analisada é, por excelência, circunscrita ao espaço do OP e às dinâmicas próprias deste. Em nosso estudo, abordamos de maneira exploratória relações com o recorte empírico da qualidade dos serviços públicos. Ao olhar para ações com tal conteúdo, não definimos a priori os espaços ou canais a circunscrever tais relações, como OPs ou conselhos.

Conforme discutido brevemente acima, o aparato analítico da literatura sobre a participação, por se focar nos espaços centralizados de participação em âmbito municipal, 294 como conselhos e OP, seus atores e dinâmicas internas, não oferece instrumentos analíticos suficientes para a análise da ação voltada para a melhoria de serviços em microterritórios e não concentrada em espaços pré-determinados.

Para nos referirmos às ações empreendidas por esses atores, organizados no nível microterritorial e que intervêm na provisão de serviços públicos, utilizamos o conceito de controle societal tal como introduzido por Gurza Lavalle e Isunza Vera (2010). Tal conceito nos permite tornar mais abrangente a análise sobre as possibilidades de interação entre atores sociais e estatais, e as formas de incidência sobre as políticas públicas, ao incluir dimensões menos formalizadas, como espaços consultivos não mandatórios, como parte do exercício do controle social. Essa inclusão é importante na medida em que não existe evidência empírica de que formas menos rigorosas de controle social, realizadas por atores coletivos e individuais em âmbito local com grau de organização e coordenação menores, não contribu- 
am para a melhoria do fornecimento de serviços públicos e das políticas públicas em geral, e para a garantia de direitos.

Controle societal é definido pelos autores de forma ampla como "a incidência de cidadãos sobre processos decisórios, seja mediante o fornecimento de informação, de determinação de prioridades, de implantação, seja mediante formas de avaliação e supervisão" (Gurza Lavalle e Isunza Vera, 2010, p.31). Ao olharmos para as interações entre os atores que buscam incidir nas políticas públicas, na fase da implementação da política e no local onde esta política, representada por um tipo de programa, é provida aos usuários, tal abordagem nos permite incorporar à análise outras ações que antecedem, complementam, reforçam e transcendem ações de accountability societal. Para os autores, responsividade e sanção são elementos fundamentais da accountability, mas constituem um subgrupo da categoria de controle societal ${ }^{4}$.

\footnotetext{
${ }^{4}$ Peruzzotti e Smulovitz (2001) definem accountability social de maneira mais rigorosa e restrita. Ela envolve ações desencadeadas por atores coletivos, societais, chamando a atenção para inovações operadas por movimentos sociais, escândalos midiáticos e imprensa investigativa que ativam e fortalecem os mecanismos de controle horizontal. Inclui mecanismos para busca de informações, prestação de contas, sinalização de preferências dos cidadãos e sanção indireta que são permanentes; mecanismos que podem ser mobilizados durante todas as fases de uma política pública. O papel dos atores sociais, neste caso, é indireta, já que o controle só é realizado efetivamente, segundo essa definição, pelas agências de controle do próprio Estado, em última instância, por atores estatais. É, portanto, uma forma exigente de controle, pois depende o suficiente de organizações centrais para promover ações que resultem em altos custos reputacionais para agentes do Estado; e indireta, pois depende de uma agência do Estado para operar o controle, o que não é necessário para a noção de controle societal aqui utilizada conforme Gurza Lavalle e Isunza Vera (2010). Apesar de envolver diversas fases das políticas públicas, o conceito de accountability social acaba por categorizar analiticamente apenas processos e mecanismos formais que, acionados, provocam a sanção sobre as ações governamentais e a justificação de ações por parte dos atores governamentais. Fogem à análise processos menos formalizados como, por exemplo, contato direto de atores sociais com políticos ou gestores, processos de negociação e encaminhamento informais de demandas etc., invisibilizando também a ação de atores de nível local (ou seja, não necessariamente organizados em grandes movimentos sociais centralizados), que se mobilizam para acionar mecanismos formais e também informais de controle das ações do Estado.
} 
Esse enquadramento permite considerar também uma maior amplitude de ações na medida em que evita focar apenas em espaços participativos, canais institucionalizados ou certos tipos de atores coletivos. De acordo com os autores,

O repertório de expedientes de controle social compõe um amplo leque que abarca desde, por um lado, formas de participação pontuais e individualizadas - algumas vezes fragmentadas como nos sistemas de queixas -, até, por outro, a participação coletiva e institucionalizada, facultada para a tomada de decisões vinculantes na operação políticoadministrativa de funções públicas (Gurza Lavalle e Isunza Vera, 2010, p. 34).

Outro ganho advindo da percepção de Gurza Lavalle e Isunza Vera é a distinção analítica imposta entre controle social e societal. O controle societal é operado apenas no 296 nível da ação coletiva, por atores coletivos organizados, mas não necessariamente formalizados, que "falam em nome de alguém” (Gurza Lavalle e Isunza Vera, 2010, p. 23). A aproximação proposta pelos autores exclui, assim, tipos de controle que podem ser realizados por indivíduos. A abordagem de controle societal nos permite incorporar à análise um leque maior de ações e de atores sobre os quais a literatura apresentada acima não desenvolveu ferramentas analíticas suficientemente satisfatórias.

\section{Análise setorial: prevendo a existência de atores coletivos locais}

Conforme exposto acima, as literaturas sobre participação e movimentos sociais deixaram alguns registros de organizações nos microterritórios nos anos 1970 e 1980, pouco dizendo a respeito da presença e do tipo de ação política empreendida por atores coletivos locais no período mais recente. Se, naquele momento, a luta das organizações locais era pelo 
acesso a serviços e equipamentos públicos no nível do bairro, atualmente o quadro de descentralização de serviços e equipamentos em áreas como saúde e assistência social é bastante distinto. Trata-se de setores que passaram por reformas nos anos 1980 e 1990 no sentido da universalização, descentralização e participação da comunidade. Novos sistemas foram construídos, novas camadas institucionais adicionadas às agências públicas e novas formas de provisão foram multiplicadas. Mesmo que a distribuição dos serviços sofra ainda desigualdades regionais, a cobertura cada vez mais ampla coloca a questão da qualidade dos serviços como um dos eixos centrais.

Embora a literatura que lida com a participação em determinados setores de políticas públicas raramente aborde a política do microterritório, ao desdobrar seus argumentos para a compreensão desse nível empírico, no caso de saúde e assistência social em São Paulo, poderia se esperar a ausência de controle societal sobre o RM a partir da ausência de atores locais identificada nas narrativas. Inversamente, é esperada sua presença no PSF, visto que o movimento popular de saúde continua ativo até hoje, ainda que restrito a algumas partes da cidade. A atuação desses atores seria reforçada pela existência de canais administrativos e participativos descentralizados, propícios para o exercício do controle social pois, apesar das semelhanças nas reformas a que foram submetidas ao longo dos anos 1990, as trajetórias setoriais se diferenciam em termos do formato institucional, da tomada de decisão, da provisão de serviços e da atuação de atores sociais.

Desde meados dos anos 1970, um amplo movimento social, que incluía profissionais de saúde e população usuária, havia se mobilizado na luta pela constituição de um sistema universal de saúde, inexistente até então. Em São Paulo, as ações do movimento visavam à instituição e melhoria dos serviços públicos nas regiões mais pobres da cidade, mais 
especificamente na Zona Leste, e incluía como estratégia a participação em conselhos populares organizados no nível local, estabelecidos junto a equipamentos de saúde, e também ações como manifestações, assembleias gerais e reuniões com representantes do poder público (Escorel, 1998; Neder, 2007). O movimento como um todo participou em diversas instâncias e comissões no nível federal ao longo da segunda metade da década de 1980, e teve um papel de destaque na criação, sem precedentes no Brasil, de um sistema único de acesso gratuito, universal e pleno à saúde, guiado pelos princípios de descentralização e participação cidadã, em 1988. Presente nos conselhos participativos e conferências setoriais, o Movimento Popular de Saúde da Zona Leste continuou sendo um ator de relevância no setor até os dias de hoje.

$\mathrm{Na}$ assistência, os profissionais do setor - assistentes sociais - eram os únicos atores coletivos mobilizados nos anos 1980 e atuavam por meio de suas organizações de repre298 sentação. Diferentemente dos seus colegas sanitaristas, não conformaram um movimento social e, apesar dos projetos e intenções, tampouco lograram organizar ou mobilizar os usuários. As entidades assistenciais, principais provedoras no setor, por sua vez, não constituíram um ator coletivo à parte, tendo optado por contatos individuais com o Estado. Semelhante ao setor de saúde, a assistência social atingiu o status de direito social e dever do Estado na Constituição de 1988, e foi regulada pela Lei Orgânica de Assistência Social (Loas) cinco anos mais tarde. Esse processo foi conduzido não apenas por agências de governo; o segmento reformista de assistentes sociais, suas organizações representativas e os cursos universitários aos quais estavam vinculados, com o apoio de algumas entidades privadas que proviam esse tipo de serviço, participaram da elaboração de propostas subsequentes para o setor, levando adiante sua aprovação e implementação.

O longo processo da implementação das reformas resultou, em meados dos anos 2000, em configurações insti- 
tucionais aparentemente semelhantes nos dois setores: funcionando dentro de um sistema descentralizado do nível federal até o município e com a participação cidadã traduzida em conselhos e conferências. Apesar das semelhanças no arcabouço institucional, os setores continuaram se diferenciando pela presença do movimento popular de saúde e da ausência do seu equivalente no setor de assistência. A configuração dos espaços administrativos e participativos em 2007 também apontava para significativas diferenças, sendo mais descentralizada e participativa na área de saúde.

O setor público de assistência social não instalou uma robusta e capilar estrutura pública na cidade. Além da Secretaria Municipal de Assistência Social (SMADS), a instância mais próxima dos cidadãos foi constituída apenas em 2002 (Yazbek, 2004a): trata-se das 31 supervisões de assistência social, que contavam com uma infraestrutura de pessoal ainda precária, dentro das quais foram adicionadas, a partir de $2005,31^{5}$ pontos de atendimento ao usuário, denominados Centro de Referência de Assistência Social, que são as "portas de entrada" do Sistema Único de Assistência Social (Suas). Sob o controle dessa camada institucional, havia uma camada heterogênea de $334^{6}$ entidades privadas que prestavam os serviços assistenciais. A estrutura da governança participativa acompanhava a mesma lógica. O setor de assistência de um município de 10 milhões de habitantes contava com um só conselho, de nível municipal, ocupado majoritariamente pelas entidades assistenciais.

Na saúde, a estruturação era mais descentralizada e densa, apesar de sofrer mudanças a cada novo governo nos últimos vinte anos. Em 2007, havia cinco supervisões operando

\footnotetext{
${ }^{5}$ Esse número vem crescendo desde 2005.

${ }^{6}$ Em novembro de 2006, a Secretaria Municipal de Assistência e Desenvolvimento Social da cidade de São Paulo estabelecia 759 convênios com 334 entidades sociais para a prestação de serviços socioassistenciais. Dados oficiais divulgados pelo Observatório de Políticas Sociais da SMADS em novembro de 2007 (Amâncio, 2008).
} 
sob o comando da Secretaria de Saúde; estas eram, por sua vez, responsáveis por 31 coordenadorias, todas instaladas e em funcionamento. Cada Coordenadoria administrava uma área com aproximadamente 300 mil pessoas, e era também responsável por uma quantidade de equipamentos públicos de saúde. Abaixo do nível das coordenações, havia equipamentos de saúde, geridos parte pelas entidades sociais, parte pela Secretaria de Saúde. Com exceção das supervisões, em todos os níveis administrativos e ao lado de cada equipamento, havia um conselho no qual os usuários ocupavam 50\% das cadeiras. Em 2007, a cidade contava com 500 conselhos de UBSs.

A partir desses diagnósticos setoriais, as diferenças, tanto em termos de trajetória quanto da estruturação institucional e presença de atores no nível municipal, dariam conta de prever as dinâmicas de atuação dos atores em relação à provisão de serviços em âmbito local. Isto é, a implementação do 300 programa no setor de saúde seria objeto de intenso controle societal nas regiões, com a presença marcante do movimento popular de saúde, enquanto o programa de assistência social, por falta de atores coletivos representando os usuários, seria desprovido de tais ações de controle.

\section{Provisão de serviços no microterritório e atores coletivos}

Para testar a hipótese deduzida da literatura - a ausência de atores que desempenham controle societal sobre a assistência social e a previsão de um determinado tipo de ator para a saúde - e compreender as formas de controle societal realizadas em nível submunicipal, onde a provisão de serviços de fato ocorre, em cada um dos setores foi escolhido um programa: o programa de atenção básica (Programa de Saúde da Família) na saúde, e o de transferência de renda (Renda Mínima) na assistência social. Os programas estudados são bastante distintos em termos da natureza do bem que proveem e nas formas de sua provisão. Em comum, ambos ser- 
vem à mesma população de baixa renda residente em bairros periféricos e constituem os mais importantes programas, em escala e orçamento, voltados a esse grupo populacional em seus respectivos setores ${ }^{7}$.

O PSF foi adotado pelo Ministério da Saúde em 1994 como uma estratégia nacional para redirecionar o modelo de assistência à saúde pautado no atendimento hospitalar curativo para a atenção básica de cunho preventivo. Foi implementado, inicialmente, nas regiões mais pobres do país. Sua expansão foi vertiginosa: de uma cobertura de 1 milhão de pessoas no primeiro ano, ele passou para quase 30 milhões de beneficiários em 2000, e 55 milhões em 2002. Em dezembro de 2008, o PSF cobria 93,2 milhões de pessoas em todo o país (Departamento de Atenção Básica, 2009). Naquele mesmo ano, em São Paulo, o programa atendia $37 \%$ da população (Montone, 2009), e a sua cobertura era mais alta nas regiões que concentram a população mais pobre (Bousquat, Cohn e Elias, 2006).

O desenho nacional do programa valoriza fortes vínculos dos profissionais de saúde com a comunidade, ainda que inclua a possibilidade de um intermediário - entidade privada de prestação de serviços - entre ela e o poder público. A equipe do PSF, composta por um médico generalista (médico da família), um enfermeiro, um assistente de enfermagem e seis agentes comunitários de saúde, se localiza na Unidade Básica de Saúde (UBS), onde funciona também um conselho gestor. Cada equipe é responsável pela atenção a 1 mil famílias, habitantes de uma área territorial específica, e o agente comunitário de saúde do PSF é um residente local que visita regularmente cada uma das

\footnotetext{
${ }^{7}$ O PSF não é voltado explicitamente aos pobres, e não tem qualquer exigência em termos de renda dos beneficiários, mas sua implementação tanto em São Paulo como em todo o país priorizou regiões com grande concentração de famílias pobres. Além disso, são esses os beneficiários que mais dependem da saúde pública, já que as classes médias e altas utilizam serviços de planos privados de saúde.
} 
200 famílias de sua responsabilidade, encaminhando seus membros para consultas com enfermeiros e médico. Uma característica nova em relação ao modelo tradicional de atendimento básico do programa em São Paulo é a sua execução por uma dezena de organizações sem fins lucrativos, contratadas para esse fim pela Secretaria Municipal.

O Programa Renda Mínima foi criado em 2001, sendo o primeiro programa de combate à pobreza em larga escala na cidade, voltado a pessoas às margens do mercado de trabalho formal. Com um ano de existência, ele ultrapassou todos os outros programas de assistência social juntos, em termos de população atendida e parcela de recursos utilizada. No fim de 2008, o governo de São Paulo esperava que o programa atingisse mais de 200 das 300 mil famílias classificadas abaixo da linha de pobreza ${ }^{8}$. O orçamento do programa em 2006, R\$ 168,9 milhões, representava $88 \%$ dos recursos da SMADS. Vale mencionar que o RM não era uma particulari302 dade do município de São Paulo. Vários governos municipais e o governo federal criaram, naquele período, programas de garantia de renda mínima mensal, visando o combate à pobreza intergeracional em grande escala e em diferentes graus dentro de uma perspectiva de direitos. Em pouco mais de uma década, programas de garantia de renda tornaram-se a principal estratégia de combate à pobreza do país.

Esses programas eram operacionalizados sem a presença dos tradicionais atores do setor, as entidades assistenciais. O desenho do programa expressava a ausência de intermediação: cada usuário recebia seu benefício da SMADS por meio de um cartão bancário, sem nenhuma intermediação ou contato adicional com as instâncias do Estado, com a exceção do cadastro, terceirizado pela prefeitura a uma empresa privada. A contrapartida do usuário se resumia a dois tipos de

\footnotetext{
${ }^{8}$ A linha de pobreza é definida a partir da renda per capita de menos de meio salário mínimo (R\$190 em 2007).
} 
condicionalidades: a frequência dos filhos na escola e o controle de vacinas, ambos monitorados por um processo gerenciado pela prefeitura.

Nesse sentido, as características dos programas reforçam as especificidades da trajetória de reformas de cada um dos setores, acima descritas.

A segunda opção metodológica pautada nas hipóteses deduzidas da literatura consistiu em escolher duas regiões que contrastam fortemente entre si: a Zona Leste, que passou por um processo de urbanização mais antigo, contou com a presença do movimento popular de saúde e hoje tem melhores condições de infraestrutura urbana; e a Zona Sul, que passou por um processo mais recente de ocupação desordenada, cuja urbanização ainda é incompleta e onde os atores do movimento popular não chegaram a se institucionalizar. Além dessas duas regiões, foram incluídas na amostra UBSs na região Sudeste. Quinze delas ${ }^{9}$ foram escolhidas em função da presença de atores coletivos do setor de saúde identificados previamente, e mais 30 foram sorteadas aleatoriamente, tendo como controle os níveis de renda até meio salário mínimo per capita - e um número relativamente alto de beneficiários do RM.

Em cada uma das 45 microrregiões, lideranças locais foram identificadas pelos pesquisadores a partir de conversas prévias com os gerentes das UBSs selecionadas e do mapeamento dos atores coletivos do bairro. Tais áreas foram percorridas com o intuito de obter informações a respeito de lideranças e entidades sociais mais ativas na região ${ }^{10}$. Em seguida, foi escolhido em cada local o ator

\footnotetext{
${ }^{9}$ Atualmente (2009) São Paulo conta com 407 UBSs, das quais 220 operam exclusivamente com o PSF.

${ }^{10}$ Foram entrevistadas 53 lideranças comunitárias, além de gestores de UBSs e de coordenadorias de assistência social nas subprefeituras. As questões se referiam ao exercício do controle societal durante os anos de 2005 e 2007 e as entrevistas foram realizados entre os anos de 2007 e 2008.
} 
coletivo mais atuante no exercício do controle societal, ou seja, que mais agia, em nome da comunidade e com o respaldo desta, em busca de melhorias na qualidade dos serviços públicos ali ofertados. A escolha foi feita com base nos seguintes critérios: participação em algum canal coletivo de mobilização, tais como fóruns de debate sobre políticas públicas, conselhos gestores em vários níveis, associações comunitárias, entidades sociais, partidos políticos ou movimentos sociais; ação coletiva voltada para o controle societal e melhoria na qualidade de serviços no setor de saúde e/ou assistência social.

A esses atores foi aplicado um questionário em que se procurava operacionalizar o conceito de controle societal adotado, considerando cinco diferentes tipos de ação cuja ocorrência no nível microterritorial seria averiguada: demandas por melhorias dos serviços públicos; participação em eventos ou reuniões com a comunidade para discutir 304 questões a respeito de serviços públicos; e participação em manifestações, passeatas, abaixo-assinados, e qualquer outro tipo de mobilização da comunidade pela melhoria dos serviços públicos; pedidos de informação a respeito da gestão dos serviços públicos; e participação em processos judiciais ou administrativos visando à melhoria dos serviços públicos. Esses tipos não excluem ações mais contenciosas ou que privilegiem o que ocorre a partir de espaços participativos; por outro lado, limitam-se a ações realizadas coletivamente, a partir de mobilizações da comunidade, por organizações ou associações formalizadas ou não, desde que reconhecidas pelos moradores como representantes de um coletivo expressivo.

Com base nas características específicas do modelo da provisão de cada um desses serviços e dialogando com a hipótese construída a partir da trajetória dos setores, seria esperado que a presença das ações de controle societal sobre o PSF pelos atores locais e sua ausência no caso da RM. 


\section{O controle societal das associações no microterritório}

Os resultados da pesquisa apontam que todos os repertórios considerados no questionário são utilizados pelos atores em ambos os setores. Ao mesmo tempo, os dados confirmam o diagnóstico da literatura para o setor de saúde, ao evidenciarem um grande número de ações: no total foram registradas 2.024 ações, das quais $82 \%$ são sobre o programa de saúde básica; porém, os $18 \%$ restantes surpreendem ao revelar a existência do controle societal sobre o RM. Se a trajetória setorial em São Paulo, na qual o movimento popular de saúde tem desempenhado um papel relevante há mais de trinta anos, pode explicar a presença deste ator, o mesmo não ocorre com a assistência social, na qual não havia, segundo a narrativa setorial, atores coletivos locais.

No entanto, o segundo dado, que analisa a distribuição das ações sobre o controle societal do PSF pelas regiões estudadas, o poder explicativo da análise setorial é solapado. As 2.024 ações, realizadas entre 2005 e 2007, foram detectadas em 41 das 45 regiões pesquisadas, o que mostra que o controle societal não se restringe a áreas como a Zona Leste e a Sudeste, nas quais o movimento popular de saúde construiu a sua história. Esse dado já aponta que o controle societal na saúde, no que diz respeito à provisão de serviços, não está atrelado aos atores detectados pelas interpretações setoriais.

O resultado seguinte confirma essa tendência: 94\% dos entrevistados realizaram algum tipo de controle societal sobre questões relativas ao PSF e, destes, apenas $11 \%$ está ligado ao movimento popular de saúde. Visto por esse ângulo, torna-se claro que o controle societal da provisão de serviços no microterritório não é de exclusividade dos atores indicados como protagonistas setoriais.

Estes três dados - a existência do controle societal na assistência social; a presença das ações de controle em todas as regiões estudadas, independentemente do histórico de mobilização em saúde; e a realização das ações de controle 
sobre o PSF por entidades não vinculadas ao movimento popular de saúde - apontam que a atuação desses atores locais não pode ser deduzida corretamente das trajetórias setoriais, que foram retratadas na seção anterior. As hipóteses e explicações construídas em nível macro (municipal e nacional), da trajetória setorial, dos atores e da estrutura de governança, não são suficientes para explicar dinâmicas locais e para compreender o controle societal realizado sobre a provisão local de serviços. Para explicá-lo - tarefa ainda por ser empreendida - é necessário recorrer às análises das dinâmicas das relações no nível do bairro.

Um dos elementos que possivelmente ajuda a explicar esses resultados é o tipo de ator responsável pelo controle societal em âmbito local. Grande parte (74\%) dos atores coletivos que realizaram controle societal sobre o PSF - e $72 \%$ dos que o fizeram no caso do RM - são associações de morado$\operatorname{res}^{11}$, atores que chamamos de generalistas pela sua atuação 306 reivindicatória de melhorias de variados serviços públicos que chegam ou deveriam chegar aos bairros. Portanto, são atores que possuem experiência na interação com diversas instâncias de poder público e suas particularidades institucionais. A análise setorial se mostra, portanto, insuficiente para captar o que ocorre entre os atores da sociedade civil e provedores de serviços no microterritório, pelo fato de tais ações não terem sido realizadas por "especialistas" setoriais, ou seja, aqueles previstos pela trajetória setorial da saúde.

Os atores responsáveis pelo controle societal no microterritório, além da sua característica generalista, não limitaram suas ações a um determinado tipo de repertório, seja mais institucionalizado, seja mais contencioso. No caso do RM, em comparação com o PSF, observamos que os atores busca-

\footnotetext{
${ }^{11}$ Os outros tipos de atores coletivos entrevistados, que realizaram pelo menos uma forma de controle social sobre o programa Renda Mínima são: movimento popular de saúde local (11\%); além de igrejas, partidos políticos e membros de conselhos gestores de UBSs (17\%). As entidades assistenciais não realizaram nenhum controle.
} 
ram mais informação ( $26 \%$ dos casos) e acionaram em maior medida o judiciário ( $12 \%$ dos casos). Por outro lado, eles utilizam com menor frequência ações que envolvem a mobilização da comunidade, como manifestações, com $4 \%$ do total, além de abaixo-assinados e assembleias, que somam $12 \%$.

Este último par de dados pode ser interpretado pelo fato de que só fazem sentido ações de mobilização comunitária quando aqueles que a realizam são capazes de identificar interlocutores tangíveis e claros nas instâncias de poder público que são, por sua vez, obrigadas a oferecer respostas às demandas apresentadas. Quando tais instâncias tangíveis não existem ou estão fechadas por alguma razão, como é o caso do RM, que não possui interfaces de interlocução previstos entre poder público e usuários, resta aos atores recorrerem a outra instância de poder, no caso, o Judiciário, que dispõe de instrumentos institucionais para pressionar o Executivo.

Figura 1

Frequência (absoluta e relativa) dos tipos de controle societal sobre PSF e RM

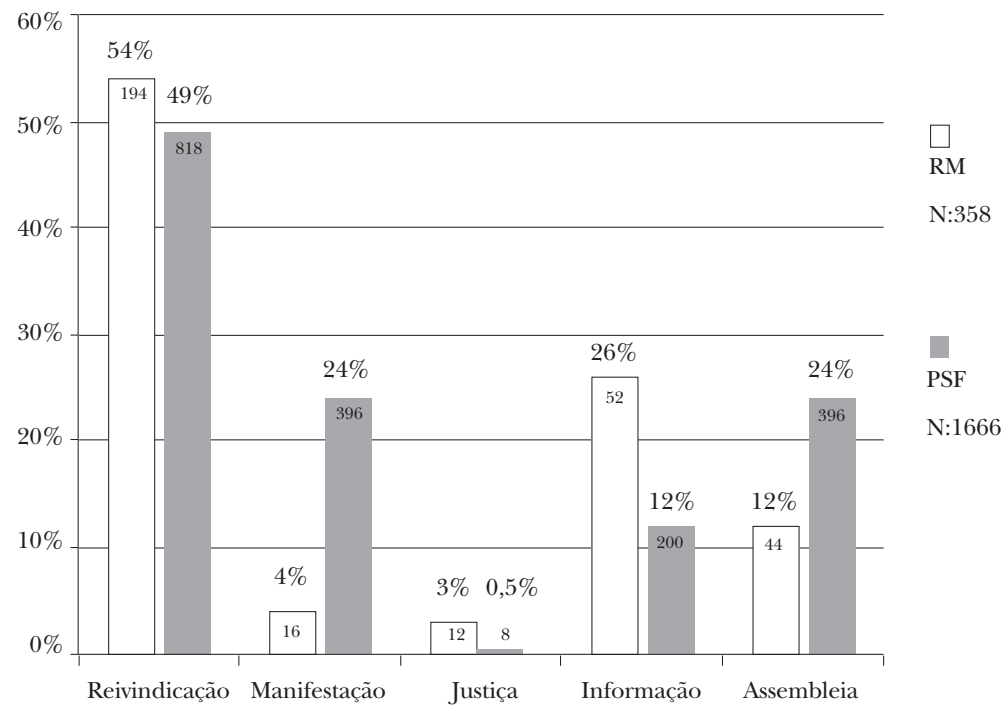


Os tipos de ação utilizados no caso do PSF e suas respectivas frequências indicam que os atores locais lançam mão de um repertório amplo. Mobilizam constantemente repertórios ditos contenciosos, como manifestações públicas, protestos, abaixo-assinados e assembleias na comunidade (24\% do total das ações, nos dois casos); recorrem também a pedidos de informação. Em alguma medida, esse resultado da pesquisa pode decorrer de fatores conjunturais. No período a que se referiu a investigação, o município era governado por uma coalizão de centro-direita (PSDB e DEM), que não tinha como prioridade estabelecer relações com instâncias participativas e organizações populares no processo decisório, e não apoiava estruturas de governança participativa.

A presença de ações de caráter contencioso não significa que os atores não utilizem canais institucionalizados, ainda que neste caso não tenha sido possível quantificar 308 o número de ações. Os canais institucionalizados identificados correspondem às instâncias do Poder Executivo e às estruturas de participação (conselhos) que respondem pela provisão ou pelo controle institucionalizado sobre os provedores. A frequência no uso desses canais traz evidências de que seu uso depende do desenho institucional. Conforme indica a Tabela 1, caso do controle do PSF, os atores percorrem todos os níveis administrativos e participativos oferecidos no setor de saúde e acessam as instâncias de uma maneira hierárquica, ou seja, concentrando ações naquelas mais próximas do nível local da provisão de serviços. A porcentagem de acessos reduz à medida que aumenta a distância entre a instância e o ator local: o nível do microterritório é indicado por $84 \%$ dos entrevistados, o intermediário por $72 \%$ e o municipal por $62 \%$. Isso demonstra a importância de instâncias administrativas e participativas descentralizadas para o exercício do controle societal da implementação das políticas. 
Para exercer o controle societal sobre o RM, a grande maioria dos atores (68\%) recorre à SMADS e, em segundo lugar, às subprefeituras $(50 \%)$ para pedir informações sobre o programa e encaminhar reivindicações. $\mathrm{O}$ fato de os atores recorrerem menos ao Conselho Municipal de Assistência Social pode ser evidência do papel secundário deste no programa ${ }^{12}$.

Tabela 1:

Canais mais procurados para o controle societal local: RM e PSF ${ }^{13}$

\begin{tabular}{|c|c|c|}
\hline Canais & RM (N=19) & PSF (N=50) \\
\hline Conselho do equipamento local & não possui & $84 \%$ \\
\hline Nível administrativo e/ou equipamento local & não possui & $84 \%$ \\
\hline Nível administrativo intermediário & $42 \%$ & $74 \%$ \\
\hline Conselho nível intermediário & não possui & $70 \%$ \\
\hline Conselho Municipal & $32 \%$ & $56 \%$ \\
\hline Secretaria Municipal & $68 \%$ & $66 \%$ \\
\hline Outros & $74 \%$ & $64 \%$ \\
\hline
\end{tabular}

\section{Considerações Finais}

Contrariando as pistas dadas pela literatura de participação cidadã, de accountability social e de políticas públicas setoriais, nosso artigo mostrou que no microterritório, onde os serviços públicos de saúde e assistência social são disponibilizados aos usuários, existe uma gama de ações de controle societal. Essas ações são realizadas por atores que denominamos generalistas, porque atuam em vários setores

\footnotetext{
${ }^{12}$ Nossa pesquisa analisou a prática de controle societal pelos conselhos municipais dos dois setores (Serafim, 2007). Demonstramos a pouca capacidade de ação do Conselho Municipal de Assistência Social (Comas) no nível local, particularmente em relação à provisão de serviços.

${ }^{13}$ Não existem conselhos de equipamentos locais ou conselhos de níveis administrativos intermediários no caso da assistência social em São Paulo.
} 
de políticas públicas sem se constituir como protagonistas de nenhum deles. Tal resultado aponta que sua atuação não pode ser depreendida das principais proposições teórico-analíticas da literatura. Sobre os tipos de ação de controle societal, a pesquisa indica a ampla variedade utilizada, desde as formas mais contenciosas até as mais institucionalizadas, o que adverte sobre os riscos de restringir a análise setorial aos espaços participativos utilizados pela literatura. Evidentemente, o uso de tais canais reflete o desenho institucional dos setores em questão, mas não pode ser explicado apenas por este, visto que, no caso do RM, os atores conseguem realizar o controle apesar de não haver instituições disponíveis para tanto, e o fazem pelas capacidades e pelo conhecimento que adquirem ao interagir com uma ampla variedade de setores, ou seja, pelo seu próprio perfil generalista.

Assim, tanto hipótese quanto explicações construídas em nível macro, tendência na qual incorrem todas as litera310 turas sintetizadas, não são suficientes para compreender as dinâmicas locais e o controle societal sobre a provisão local de serviços. Para explicá-los, parece necessário recorrer às análises das dinâmicas das relações nos microterritórios e, principalmente, é preciso desenvolver um conhecimento empírico e analítico mais aprofundado sobre esses atores, sobre os quais a literatura pouco diz.

Os resultados aqui apresentados têm caráter exploratório e apenas apontam para a necessidade de se olhar para esses territórios e formas de ação coletiva a partir de arcabouços analíticos menos restritivos e com a perspectiva de desvelar esses outros sujeitos e suas formas de interagir com o Estado. O conhecimento produzido a partir de tal prisma pode não somente contribuir para o debate sobre a construção democrática enquanto campo de estudos como também para ampliar a percepção de gestores e formuladores de políticas públicas em relação aos sujeitos com os quais eles, de fato, lidam. 


\section{Júlia Moretto Amâncio}

é pesquisadora do Cebrap, doutoranda em ciências sociais na Unicamp e bolsista do CNPq.

\section{Lizandra Serafim}

é pesquisadora do Cebrap, doutoranda em ciências sociais na Unicamp, bolsista do CNPq.

\section{Monika Dowbor}

é pesquisadora do Cebrap, doutoranda em ciência política na USP e bolsista Capes.

\section{Referências Bibliográficas}

ABERS, R. 2000. Inventing local democracy: grassroots politics in Brazil. Boulder: Lynne Rienner Publishers.

ABERS, R.; VON BÜLOW, M. 2011. "As transformações do estudo dos movimentos sociais: como estudar o ativismo através da fronteira entre Estado e sociedade?". Paper apresentado em Whatever Happened to North-South. São Paulo.

ARRETCHE, M. T. S. 2002. "Federalismo e relações intergovernamentais no Brasil: a reforma de programas sociais”. Dados, v. 45, n. 3, pp. 431-457. AMÂNCIO, J. M. 2008. Parcerias entre estado e sociedade civil: significados e desafios na gestão de políticas públicas. O caso da assistência social em São Paulo. Dissertação de mestrado. Campinas: IFCH-Unicamp.

AVRITZER, L. 2003. "O orçamento participativo e a teoria democrática: um balanço crítico". In: . ; NAVARRO, Z. (orgs.). A inovação democrática no Brasil: o orçamento participativo. São Paulo: Cortez, pp. 13-60.

BAIERLE, S. 2000. "A explosão da experiência. Emergência de um novo princípio ético-político nos movimentos populares urbanos em Porto Alegre”. In: ALVAREZ, S. E.; DAGNINO, E.; ESCOBAR, A. (orgs.). Cultura e política nos movimentos sociais latino-americanos (novas leituras). Belo Horizonte: Ed. UFMG, pp. 185-217.

BAIOCCHI, G. 2001. "Participation, activism, and politics: the Porto Alegre experiment and deliberative democratic theory". Politics $\mathcal{E}^{\circ}$ Society, v.29, n.1, pp. 43-72.

BOSCHI, R. R. 1987. A arte da associação: política de base e democracia no Brasil. São Paulo/ Rio de Janeiro: Vértice; Iuperj. 
BOUSQUAT, A.; COHN, A.; ELIAS, P. E. 2006. "Implantação do Programa Saúde da Família e exclusão socioespacial no município de São Paulo, Brasil”. Cad. Saúde Pública, v. 22, n. 9, pp. 1935-1943.

COELHO, V. S. P. 2007. “A democratização dos conselhos de saúde: o paradoxo de atrair não aliados”. Novos estudos, n. 78, pp. 77-92.

COHN, A.; Elias, P. E. M. (orgs.) 2005. Descentralização e saúde no estado de São Paulo: as articulações entre as esferas do governo. São Paulo: Cedec.

CORTÊS, S. M. V. 1998. "Conselhos municipais de saúde: a possibilidade dos usuários participarem e os determinantes da participação”. Ciência e Saúde Coletiva, v. 2, n. 1, pp. 6-17.

CORTÊS, S. M. V. et al. 2009.“Conselho Nacional dsae Saúde: histórico, papel institucional e atores estatais e societais." In: (org.).

Participação e saúde no Brasil. Rio de Janeiro: Ed. da Fiocruz, pp. 43-74.

DOIMO, A. M. 1995. A vez e a voz do popular: movimentos sociais e participação política no Brasil pós-70. Rio de Janeiro: Relume Dumará.

ESCOREL, S. 1998. Reviravolta na saúde: origem e articulação do movimento sanitário. Rio de Janeiro: Ed. da Fiocruz.

FELTRAN, G. S. 2010. "Margens da política, fronteiras da violência: uma ação coletiva nas periferias de São Paulo”. Lua Nova, n. 79, pp. 201-233.

312 FUKS, M. 2007. "Contexto, regras e efetividade deliberativa: considerações a respeito dos conselhos de Curitiba”. In: AVRITZER, L. (org.) A participação social no Nordeste. Belo Horizonte: Ed. UFMG, pp. 156-174.

GOHN, M. G. 2010. Movimentos sociais e redes de mobilizações civis no Brasil contemporâneo. Petrópolis: Vozes.

GURZA LAVALLE, A. 2003. "Sem pena nem glória: o debate da sociedade civil nos anos 1990”. Novos Estudos, n. 66, pp. 91-110.

; BUENO, N. S. [prelo]. Sociedade civil e intermediação política.

Associações de bairro e ONGs em duas metrópoles latino-americanas.

; ISUNZA VERA, E. 2010. "Precisiones conceptuales para el debate contemporáneo sobre la innovación democrática: participación, controles sociales y representación”. In: La innovación democrática en América Latina: tramas y nudos de la representación, la participación y el control social. México: Centro de Investigaciones y Estudios Superiores en Antropología Social - Universidad Veracruzana.

LÜCHMANN, L. H. H. 2002. Possibilidades e limites da democracia deliberativa: a experiência do Orçamento Participativo de Porto Alegre. Tese de doutorado. Campinas: IFCH-Unicamp.

MARQUES, E. C. 2005. "Redes sociais e poder no Estado brasileiro: aprendizados a partir das políticas urbanas”. Disponível em $<$ http:/ /www. 
centrodametropole.org.br/index.php?section=content\&subsection_ id=5\&content_id=549>. Acesso em 10/06/2011.

MARQUETTI, A. 2003. "Participação e redistribuição: o orçamento participativo em Porto Alegre”. In: AVRITZER, L.; NAVARRO, Z. (orgs.) A inovação democrática no Brasil. São Paulo: Cortez, pp. 129-156.

MELO, M. A. 2005. "O sucesso inesperado das reformas de segunda geração: federalismo, reformas constitucionais e política social". Dados, v. 48 , n. 4 , pp. $845-889$.

MESTRINER, M. L. 2005. O estado entre a filantropia e a assistência social. São Paulo: Cortez.

MONTONE, J. 2009. “A saúde pública na cidade de São Paulo”. Disponível em <http:/ / sistema.saude.sp.gov.br/eventos/ Palestras/30-11-2007\%20-\%20Seminario/Mesa_5\%20O\%20 Processo $\% 20$ de $\% 20$ implementacao $\% 20$ do $\% 20$ pacto $\% 20$ pela $\% 20$ saude $\% 20 \mathrm{e} \% 20 \mathrm{do} \% 20$ plano\%20estadual/Januario_Montone.pdf $>$. Acesso em 20/03/2009.

NAVARRO, Z. O. 2003. "Orçamento participativo de Porto Alegre (1989-2002): um conciso comentário crítico”. In: ; AVRITZER, L. (orgs.). A inovação democrática no Brasil: o orçamento participativo. São Paulo: Cortez, pp. 89-128.

NEDER, C. 2007. Participação e gestão pública: a experiência dos movimentos populares de saúde no município de São Paulo. Dissertação de mestrado. Campinas: FCM-Unicamp.

PERUZZOTTI, E.; SMULOVITZ, C. (eds.) 2001. Controlando la política: ciudadanos y medios en las nuevas democracias. Buenos Aires: Editorial Temas.

POGREBINSCHI, T. 2010. "Participação como representação: conferências nacionais e políticas públicas para grupos sociais minoritários no Brasil”. In: Anais do 34º Encontro Anual da Anpocs.

RAICHELIS, R. 2000. Esfera pública e conselhos de assistência social: caminhos da construção democrática. São Paulo: Cortez.

SADER, E. 1988. Quando novos personagens entraram em cena: experiências, falas e lutas dos trabalhadores da Grande São Paulo, 1970-80. Rio de Janeiro: Paz e Terra.

SERAFIM, L. 2007. "Controle social nos conselhos municipais de assistência social e saúde de São Paulo”. Relatório da pesquisa Reforma de serviços públicos: o papel da ação coletiva e da accountability social (Nova Delhi e São Paulo). IDS/CEBRAP (mimeo).

SILVA, E. R. 2009. "Participação social e as conferências nacionais de políticas públicas: reflexões sobre os avanços e desafios no período de 
2003-2006”. Disponível em <http://www.ipea.gov.br/portal/images/ stories/PDFs/TDs/td_1378.pdf>. Acesso em 24/10/2011.

SILVA, M. K. 2003. A expansão do Orçamento Participativo na região metropolitana de Porto Alegre: condicionantes e resultados. In: L. AVRITZER e Z. NAVARRO (orgs.), A inovação democrática no Brasil. São Paulo: Cortez, pp. 157-185.

2010. "De volta aos movimentos sociais? Reflexões a partir da literatura brasileira recente”. Ciências Sociais Unisinos, v. 46, n. 1, pp. 2-9. SOUZA, C. 2003. "Estado do campo: da pesquisa em políticas públicas no Brasil”. Revista Brasileira de Ciências Sociais, v. 18, n. 51, pp.15-20. SPOSATI, A. 2007. A menina Loas: um processo de construção da assistência social. São Paulo: Cortez.

TATAGIBA, L. 2007. "Movimentos sociais e sistema político: um diálogo (preliminar) com a literatura”. In: Anais do 6ํㅡㄹ Encontro da Associação Brasileira Ciência Política.

; TEIXEIRA, A. C. C. 2005. Movimentos sociais e sistema político: os desafios da participação. São Paulo: Pólis/PUC-SP.

TEIXEIRA, A. et al. 2007. Habitação: controle social e política pública. São Paulo: Instituto Pólis/PUC-SP. .; KAYANO, J.; TATAGIBA, L. 2007. Saúde: controle social e política pública. São Paulo: Instituto Pólis/PUC-SP.

YAZBEK, M. C. 2004a. Assistência social na cidade de São Paulo: a (difícil) construção do direito.São Paulo: Instituto Pólis/PUC-SP. 2004b. "As ambiguidades da assistência social brasileira após dez anos de Loas”. Serviço Social E̋ Sociedade, n. 77, pp. 11-29.

\section{Outros materiais}

DEPARTAMENTO DE ATENÇÃO BÁSICA (DAB). 2009. "Atenção básica e saúde da família”. Disponível em <http://dtr2004.saude.gov.br/dab/ abnumeros.php>. Acesso em 20/03/2008. 